\title{
INTERPRETATION OF THE WRITTEN LAW
}

It is sometimes said that law is applied logic, and almost always the person making this statement has in mind exclusively the deductive or analytical form of logic. Obviously this epigrammatic statement has a very strong foundation of truth. Deductive logic is a mental operation the lawyer must employ many times every day. The application of law to given states of fact commonly proceeds by a series of syllogisms, in such manner that the rule of law forms the major, the facts the minor premise, and the resulting conclusion the judgment: Whoever kills another is guilty of homicide; $A$ has killed $B$; therefore $A$ is guilty of homicide.

It is the purpose of this paper to show that this form of reasoning is by no means, as has frequently been imagined, the only form which legal science employs, but that the opposite or inductive form is constantly called in to aid the finding of a just conclusion. This also is by no means a novel proposition, but it would seem that the necessity for inductive or synthetic reasoning is more often vaguely felt than clearly recognized. This feeling sometimes gives rise to the criticism of decisions as being "scholastic," meaning that they are based altogether on deduction from an assumed minor premise; without regard to the specific social circumstances of the case which can be brought into the reasoning only by an inductive or synthetic process.

Our considerations will be confined principally to legal logic as applied to the written law, in the hope that we may not only help to obtain a clearer view of the process of interpretation in general, but throw some light on the question, in what cases a so-called strict construction of constitutions and statutes is proper, and under what circumstances the obvious meaning of the text should be extended by what is commonly called liberal or broad interpretation to subjects not at first glance covered by the wording of the act. Heretofore the choice of one or the other of these methods has rarely been made with clear consciousness of the reasons, but rather on the basis of subjective predilections influenced by temperament, training, political convictions, economic or social preferences. The subject is far too vast to be treated exhaustively in a brief magazine article, and the most we can do therefore is to suggest some new points of view from 
which a more elaborate survey of the subject may be made in the future.

We shall begin with calling attention to several different directions in which one may travel when he attempts to interpret the meaning of written laws. It seems that anyone looking for principles of interpretation would first hit upon the rather obvious idea that the statute should be given the meaning which will express the actual intention of the legislator when the law was enacted. Consequently we find this principle widely advocated, and historically it is probably the first to be maintained. Soon, however, difficulties were discovered in following out this theory. Who is the legislator? The legislative body which passed the act? Then we shall almost invariably find that different members understood the meaning differently. Even if we confine the term "legislator" to the majority voting in favor of adopting the bill, that may still be the case. How then shall we determine what the legislator really meant? By analyzing the debates? They may not be fully reported. By listening to the opinions of members after the passage of the act? That would be plainly impracticable. Sometimes it is suggested that the legislator is not the body which by an authoritative vote enacted the bill into law, but rather the person or persons who drew the bill. That, however, would get us little farther. For we should still have to find extraneous evidence to discover what the draftsmen meant, the moment a doubt arises. In other words, to interpret a statute in accordance with the intention of the legislator may seem superficially reasonable, but involves in many cases an inquiry into facts, where the evidence would either be wholly lacking or else be exceedingly voluminous and in all cases uncertain to the highest degree, so as to make it quite unadapted to the practical work of administering justice.

In the face of these difficulties, a second theory has obtained wide sway. According to this, the actual intention of the legislator is quite immaterial; what matters is the way in which he has actually expressed his intention. We must look to the wording of the statute, and to that alone. This theory would, no doubt, work admirably if all statutes were models of legislative style, and expressed with perfect lucidity, without an unnecessary word nor lacking any expression needed to make the meaning clear. If that were the character of our statutes, as a matter of fact, we should not need to bother about any theory of interpretation; every act would explain itself. We all know, 
of course, that statutes are very far from well-drawn, as a rule. The very manner of their adoption, by being subject to amendment in the heat of debate, prevents their being perfectly clear; it is even said that sometimes they are intentionally made ambiguous, in order to induce various classes of members to vote for them who really have quite inconsistent legislative intentions. All this is true in every country where laws are made by large bodies, but in the United States we have the trouble in an aggravated form, on account of our somewhat extraordinary belief that any person capable of dictating to a stenographer, and certainly every person who somehow has managed to be admitted to the bar of some court and consequently may call himself a lawyer, is quite competent to draw a legislative bill. Under these circumstances, the interpretation of a statute and the construction of its ambiguous passage is one of the most difficult tasks to which trained intelligence may be applied.

This theory, however, is most generally adopted among lawyers, and finds expression in innumerable decisions. The difficulties of the task have led the courts to adopt a number of logical subterfuges, the sophistical nature of which is really apparent to all who look beneath the surface, but which are tacitly accepted as sufficient whenever they result in the realization of substantial justice. For after all, legal science and the courts exist for the practical purpose of maintaining social order and not for the sake of vindicating the principles of logic.

It would be impossible to enumerate, and still less to analyse, the great variety of these devices by which the courts seek to read into poorly drawn statutes practical meanings they do not really express. Any text book on the subject will furnish in the cases it cites an abundant crop of illustrations. Some of these devices have been fortified by a set of presumptions which by long tradition have assumed the character of legal rules. Thus it must be presumed that the meaning of the statute cannot be an absurdity; that every part, down to the individual words and even the commas and other punctuation, has a meaning; that the legislature intended to do nothing unconstitutional; that it acted in the light of full knowledge of the whole system of the law, not to mention various other presumptions enumerated in the text books. ${ }^{1}$ Another favorite device is that of using a word

${ }^{1}$ The following illustrative cases might easily be multiplied: City of Jefferson v. Weems, 5 Ind. 547; In re Low Yam Chow, 7 Sawy. 546; Bailey v. Commonwealth, $74 \mathrm{Ky}$. 688; French v. Teschemaker, $24 \mathrm{Cal}$. 518; Little v. Bowers, 48 N. J. L. 370 . 
in a sense which it has never borne before, and of which the legislator, whoever he be, pretty certainly never dreamed, but which will indeed make the statute practicable-which as was said above is really the primary purpose of courts of law. An illustration of this sort of twisting a word from its meaning is the universal inclusion of typewriting in the meaning of "writing" as used in statutes passed long before typewriters were invented. As a matter of fact, the typewriter is far more analogous to the printing press than to the pen, and there was a brief hesitation whether its use should not be classed as printing, rather than writing. ${ }^{2}$ The obviously inconvenient results which would have flowed therefrom caused the court to let logic give way to practical sense. In connection with the same word "writing" an even more extraordinary instance of twisting the sense to get practical results is found in copyright law. The only authority Congress has for legislating on the subject is found in Art. I, $\S 8$, subs. 8, U. S. Constitution, where power is given to protect the "writings of authors." In the very first copyright act passed by Congress, maps and charts were included as "writings." These, as well as drawings and paintings, may at least be made by a manipulation similar to writing, with pen, pencil or brush; but how can that be said of photography and sculpture? Yet by common consent these are included among the legitimate subjects of federal copyright. The court has not even deemed it worth while to argue the case at length. ${ }^{3}$

The complications arising out of the interpretation of statutes from the text of the act alone are increased by the fundamental principle regarding the development of American law, the rule of "stare decisis." Historically, the principle of interpreting according to the intention of the legislator was well established by precedent before its difficulties were realized. Consequently, the courts were unable to abandon it frankly and in so many words. That would have been "judicial legislation," which according to another doctrine well established by judicial and legislative precedent, is an encroachment on the prerogative of the legislative branch of the government. Accordingly, courts and text book writers continue solemnly to declare that to-day

\footnotetext{
'See Franco-American Loan \& Building Association v. Joy, 6r Mo. App. 102; State v. City of Oakland, 69 Kans. 784.

${ }^{3}$ See Sarony v. Burrow-Giles Lithographing Co., 17 Fed. Rep. 591, for photography. The question of sculpture as "writing" has never even been raised in court, it seems.
} 
as ever the object of interpretation is to discover the intention of the legislator. This principle "is universally recognized, is constantly stated by them as the basis for their action in matters of this kind, and is supported by the unanimous voice of the authorities." All of which is perfectly correct.

At the same time we have already seen that at an early date the courts, while nominally maintaining the earlier doctrine, in reality applied the second doctrine of interpretation, according to which it does not matter what the legislator really intended, but only what he has actually expressed in the statute or constitution. We are bound to assume that whatever we can read out of, or into, the text, by the help of the presumptions and other devices mentioned above, is the intention of the legislator. As a matter of fact, we know positively in some cases, and have most excellent reasons to suspect in others, that the legislature at least, if not the actual author of the bill, never did intend anything of the sort. Yet the courts are entirely justified in making these assumptions. Their business is to maintain social order, not to vindicate the claims of logic. They must interpret statutes so as to make them adequate to the needs of society, and they must recognize the rule of "stare decisis" or the whole fabric of our legal system may collapse.

However, precisely as the courts have not, in reality, adhered to the original doctrine of the intention of the legislator, they have not remained bound by the supplemental theory of finding the meaning from the text alone. How could they do so, in those cases where there actually was no meaning to some provision of the statute, or at least no meaning that could be reasonably applied to some of the states of fact it was apparently intended to cover? Consequently the strictness of the principle was mitigated by the rule, that in such cases certain vague formulae may be called into action which are to put into the statute whatever may be necessary to make it a practicable rule even though the text by itself be nonsensical. Such formulae are "the spirit and reason of the law," "the scope and purpose of the act," sometimes even the "equity and convenience of the case." All these are equally useful also when the difficulty is not so much that the statute has no intelligible meaning, as that it has several

\footnotetext{
'Black on Interpretation of Laws, p. 47. Note the formidable list of cases cited in the same place.

'Associates, etc. v. Davison, 29 N. J. L. 4I5.
} 
possible meanings among which a choice must necessarily be made.

Now the question arises, naturally, how are these formulae themselves to be interpreted? For taken as they stand, there is hardly any concrete meaning in them at all; they are like a frame work which must be filled up with the definite and tangible material they are intended to hold.

This is the point where analytical or deductive reasoning no longer suffices. The characteristic of that form of thinking is that the very result of our reasoning is already contained in the premise from which we start. All we have to do is to bring it to light. Now, however, we have come to a point where there is no content-we have merely a frame work, a phrase, or to use a philosophical term, a "form," such as "the spirit and reason of the law." The only way in which we can discover the material to fill the frame work is to observe the external facts of the subject matter-including among "facts" not only sensual but also psychological phenomena. From a large number of observed cases of similar nature we may then gather, by induction, a proposition regarding some quality common to all of them. This common quality will be the matter with which we may fill our frame work-in other words, it will be the "spirit and reason of the law," the "scope and purpose of the act," or the "equity and convenience of the case." We may still call this sort of interpretation an attempt to find the will of the legislator, by assuming that the legislator must have made the same sort of observation of external facts as we have made, and fitted his statute to suit them. That may or may not be actually true-obviously, it ought to be true in all cases. It is possible, however, that the facts to be observed are different when the court is called upon to interpret the law from those existing when the legislator made it. Then the question must come up: Which set of facts is to be considered? If we are to make those before the eyes of the legislator the basis of interpretation, we shall not only run the risk of not being able to get a thorough knowledge of data that may have disappeared in the interval, but also the much greater danger of giving to the statute a meaning entirely inappropriate to existing circumstances. We should be playing into the hands of radicals afflicted with the reforming mania, while it is one of the essential qualities of every well-organized system of law to be conservative. 
If, however, it is conceded that the circumstances from which we may learn the spirit, the reason, scope or purpose of the law are the circumstances of the present, we may from the fact that the legislator as well as the interpreter must look to external facts for his guidance obtain a hint regarding the true foundation principle of interpretation. This is neither the will of the legislator, pure and simple, nor the will of the legislator as he has actually expressed it in the text of the statutes. In all cases of doubt regarding the meaning of the words, the text should be construed to mean that which the legislator would himself have expressed if he had been in possession of all the relevant facts which the court finds to exist at the time of rendering its decision. This does not mean, of course, that the court is to be at liberty to substitute for the provisions of the statute other provisions which he deems to be more closely adapted to the circumstances of the time, but that of several possible constructions that is to be chosen which is most apt, under the circumstances actually existing, to lead to the desired result, to wit: the maintenance of social order.

By following this rule, we shall accomplish a double end: We are thereby recognizing the fact that the social order changes, and that a legal provision which had indisputably beneficial effects a hundred years ago may not have the same good results if applied to-day in precisely the same manner. We may conceive for instance, that in the year I790 every consideration of good order and morality would lead a Connecticut judge to construe the Sunday law as forbidding a young farmer to take his sweetheart for a pleasure drive on Sunday afternoon, while in the year I9I5 a provision expressed in precisely the same words in a Wisconsin statute would not be interpreted as prohibiting a chauffeur from driving his employer through the park during church time. The other result obtained by adopting a principle of interpretation such as we have formulated above is the recognition of the fact that the meaning of words changes in the course of years, so that an interpretation reasonable enough at one time becomes quite unreasonable at another. The case of the typewriter, cited above, seems again to be as good a case as can be found. At the present time to print on the typewriter is called writing even in ordinary conversation, while surely in I800 nobody would have included any of the forms of printing then known within the term "writing." 
It would seem to be no more unreasonable to indulge in the presumption that the legislator intended his statute to establish a principle, the application of which may be modified in accordance with changing circumstances, than to indulge in any of the other presumptions which by numerous precedents are made unquestioned parts of the law of interpretation. Certainly it is no more so than the presumption, or rather fiction, that in passing a statute the legislature was aware of and actually considered the whole body of our common and statute law, not to mention equity. As a matter of fact we know that, during the life of a statute, as one case after the other comes up under it showing some few of the infinite combinations of fact that are possible but cannot be foreseen by any human being, a number of relations between the statute and other rules of law are discovered which the legislator could not possibly have had in mind when he enacted the statute. Nor is our proposed rule of interpretation farther from the actual facts of the legislative process than the other unquestioned principle of interpretation according.to which every word and syllable of the act is presumed to have a carefully calculated meaning and purpose. In reality we know that the text of very many statutes is carelessly drawn without the slightest realization of the difficulties a single ill-chosen word, a single awkward grammatical construction, or one superfluous phrase may cause to litigants and courts. On the other hand, it would seem natural enough that a legislature composed of intelligent members actually did recognize the truth that social circumstances, including the meaning of words, are in a constant flux, and that the interpretation of the text at any given time ought to follow these changes, as long as the principle contained in the act is maintained; in fact they may well be presumed to realize that the principle can often be maintained only by adapting the interpretation of details to the changes of external circumstances. It may be asserted, therefore, that our canon of interpretation, according to which in cases of doubt that construction must be chosen which the legislator would have expressed if he had legislated at the moment when the interpretation is made, is entirely in harmony with the traditional theory of finding the intention of the legislator, subject to the accepted presumptions. The legislator may reasonably be presumed to have intended precisely that rule.

As a matter of fact, the rule has been followed, in proper cases, a great many times, although the true reason for it has 
not been supplied, it seems, in any of the published decisions. In at least two fields of law, the courts are proceeding in this manner constantly, although they rarely take occasion to set out their steps of reasoning further than to refer to those vague formulae we have described above as mere frame works. These two fields are that of municipal ordinances and by-laws of other corporations, the validity of which is attacked on the ground that they are unreasonable; and the much wider province of the police power. In all these cases, the question of the true scope and meaning or the validity of a statute or by-law must necessarily be decided in the light of all the surrounding circumstances which may either be such as are within the judicial knowledge of the court or may appear from the evidence in the case. In all these instances, the mental operation. by which the court arrives at his decision is clearly that which we have described, the observation of a large number of facts and the recognition of their common characteristics, which is tested by the fundamental purpose of maintaining the social order and thus becomes "the reason and spirit of the law."

The presumption regarding the intention of the legislator that the principle enacted by his statute shall be interpreted so as to adapt its applications to the successive changes in the social environment, also suggests what may be the true theory of the different ways of interpreting which go by the name of strict or narrow construction on the one hand and liberal or broad construction on the other. The presumption implies that there is a difference between what we have called the principle, constituting a broad, general provision to accomplish certain ends, and the applications which refer to the method by which this general provision can be made effective in each particular state of facts. This method of making the principle effective as applied to some particular state of facts may be called the rule of the case. The difference between a principle and a rule thus indicated is not confined to the written law; it pervades the whole realm of legal action. For instance, it is a principle that no person shall be deprived of life, liberty or property without due process of law. It is a rule, by which this principle is made effective, that every person unlawfully deprived of his liberty shall be entitled to a writ of habeas corpus. From the illustration just given it is apparent that rules, as distinguished from principles, may themselves be of a general nature and embodied either in the common law or in constitutions and statutes. 
Now it appears to me that in this distinction between principle and rule we have the clue to the question regarding the occasions when a liberal and when a strict construction of a statute or other written law is proper. Provisions embodying principles should be liberally construed; mere rules, on the other hand, are not to be extended beyond their expressed meaning.

This proposition is sure to be misunderstood unless we first take the trouble of clearing our minds regarding the precise meaning of liberal and strict construction.

Every legal provision, as in fact every expression of thought, in human language, contains what is known as a concept or notion of some thing or action, either physical or mental. The concept comprehends a number of qualities or attributes which in the aggregate constitute a class. These attributes are not all represented in the mind with equal clearness, when the concept is thought of. Just as in physical vision only one point in the field covered by the eye is perceived with entire distinctness, while all others are seen in various degrees of indistinctness, increasing towards the periphery of the field, so the mental vision will concentrate attention with clearness on one or a very few. of the attributes constituting the concept. Around this there will be a twilight zone; but by shifting the attention a little, a new point will be brought into distinctness and the extent of the concept will be changed although the identity of the concept is not destroyed. It is impossible, therefore, to draw sharply defined lines around any concept; there will always be a zone of which one cannot say with positiveness that it is or is not within it.

Strict construction may be defined as that method which refuses to include within any concept it finds in the text of the law anything except the point that is perfectly clear in the mental field of vision. Liberal construction, on the other hand, includes within the concept more or less of the surrounding zone indistinctly perceived when the attention is directed to the central point of the concept. A construction, however, is not liberal simply because, in the course of social change, the word expressing a concept has altered its meaning. Thus it is in the case of the concept "writing." If to-day we include therein printing on the typewriter, it is not because we now give to the term a liberal construction while formerly it was construed strictly. We are still using, so to speak, only so much of the concept "writing" as is within the clear mental vision of any person expressing it, for everybody now means to include typewriting when he says 
"write." One may say, therefore, that the ancient concept of writing has changed to something else by society-in this case by extending it to cover an activity somewhat different in character from the ordinary forms of writing. In other cases, the social change may be in the direction of narrowing the field, or it may be a transposition to an entirely different set of attributes. Such social extension, however, is not meant by the term liberal construction. That expression is applicable when the interpreter himself extends the meaning of a term to something which lies merely within the twilight zone surrounding the clearly understood notions in a concept, but is not usually included by the person employing the term. For instance, a town ordinance may regulate the running at large of "horses and cows" on the highways. It would be a.legitimate use of liberal construction if the court were to extend the concept cow to cover a heifer, although none of the farmers of the neighborhood would ever dream of calling a heifer a cow.

The court, construing such an ordinance, will discover from his examination of the social circumstances, such as the amount of traffic on the highway, the mischief such animals may be expected to do if allowed to run at large, and the trifling character of the inconvenience the restriction imposes on the owners, the reason for and scope of the law, that is, the extent which the framers of the ordinance meant to give to the principle thereby established. Accordingly, he very properly extends the ordinance to similar animals not expressly mentioned. Now let us suppose that the ordinance directs the path-master, hog-reeve or other rustic dignitary to take animals found at large to the public pound. That provision would not be a principle but a rule, designed to put the principle of keeping animals under restraint into effect. Would the court be justified in construing this provision broadly so as to allow the hog-reeve to take the guilty heifer to his own barn instead of the public pound? Clearly not. For the public pound was established for the express purpose of enabling the owner to find his obstreperous ward and getting her out of prison by paying fine and fees. If the animal might be taken elsewhere, this purpose could not be accomplished.

The reason why in the one case a liberal and in the other a strict construction appears most conducive to attaining the single end all law has in view, to wit: the maintenance of social order, seems to appear clearly enough from the simple illustration just furnished. A legal principle is a regulation covering a relatively 
broad field of social activity. Within the concept embodying it, there are comprised a great many things, each of which might become the center of attention without producing in the mind of the thinker the feeling that it is no longer even within the twilight zone of the concept-that as a matter of fact the uttermost boundary of the concept has been exceeded. The opposite is true of a mere rule. This covers a narrow field only-and the moment you step aside from the center of the concept you are in danger of transgressing the outer boundary surrounding the group of ideas forming the narrow concept embodied in the rule.

If this general principle of interpretation, according to which the concepts used in a legal provision may be interpreted to include their twilight zones whenever the provision embodies a principle (liberal construction), but should be confined to the things clearly within the mind of the speaker when he uses the word expressing the concept in cases of mere rules (strict construction), is tested by the accepted canons, such as that remedial statutes should receive a liberal, penal provisions a strict construction, it will be found to be entirely in consonance with them. It seems to me, however, that the application of the canons will become easier and less arbitrary than it now is when the underlying principle as here set out is thoroughly understood. The principle, however, will probably be found to be incompatible with those traditional rules from which the more modern decisions are trying to emancipate themselves. I have in mind particularly the ancient precept that "statutes in derogation of the common law must be strictly construed." This and a few other traditional rules cannot, it must be admitted, be reconciled with the principle advocated above. To discuss the question whether the principle or the traditional rules should be preferred, would require a separate magazine article, to say the least. For it would involve the whole problem of the mutual relations of the common and the written law, and the value of each as a source of legal principles.

Washington, D. C.

ERnest Bruncken. 